\title{
Análise espacial de atributos do solo e cobertura vegetal em diferentes condições de pastagem
}

\author{
Durval N. Neves Neto', Antonio C. dos Santos' ${ }^{1}$, Perlon M. Santos', \\ Jonahtan C. Melo' ${ }^{1} \&$ Josemara S. Santos ${ }^{1}$
}

\begin{abstract}
RESUMO
As áreas destinadas à pecuária têm-se expandido sobre áreas de vegetação nativa promovendo transformações na qualidade do solo. O objetivo foi avaliar os atributos de um Neossolo Quartzarênico sob diferentes coberturas vegetais para saber se a degradação do pasto representa a degradação do solo. As áreas avaliadas foram: floresta nativa; capoeira; pastagem sem controle de lotação animal; pastagem em pousio; pastagem com invasoras; pastagem degradada com solo descoberto e invasoras, pastagem degradada com invasoras e espécies arbóreas e pastagem com baixa produção de forragem. Todas as pastagens eram formadas pela gramínea Brachiaria brizantha cv. Marandu. Realizaram-se 128 amostras de solo nas profundidades de 0-5 e 5-10 cm, dentro de cada área de manejo considerada como parcela experimental e a cobertura do solo foi quantificada. Foram mensuradas propriedades químicas e físicas do solo. Os dados foram submetidos a estudo geoestatístico. Foram constatados aumento na resistência mecânica à penetração e diminuição nos teores de matéria orgânica nas áreas mais degradadas. Pasto degradado não representa necessariamente solo degradado enquanto solo degradado está relacionado a pastagem degrada.
\end{abstract}

Palavras-chave: degradação ambiental, geoestatística, interface solo-planta, manejo de pastagem

\section{Spatial analysis of soil attributes and cover vegetation under different grazing conditions}

\begin{abstract}
The areas for livestock raising have expanded into areas of native vegetation, promoting changes in soil quality. The objective of this study was to evaluate the attributes of a Entisol under different vegetation covers to whether the pasture degradation represents soil degradation. The areas evaluated were: native forest, shrub, uncontrolled grazing animal stocking, grazing in fallow pasture with weeds; degraded pasture with bare soil and weeds, degraded pasture with weeds and tree species and grassland with low forage production. All pastures were formed by Brachiaria brizantha cv. Marandu. Hundred and twenty eight soil samples were collected in 0-5 and 5-10 cm, within each management area, considered as an experimental plot and soil cover was quantified. The chemical and physical properties of the soil were measured. Data were subjected to geoestatistical study. Increase in penetration resistance and decrease in the levels of organic matter were observed in the most degraded areas. Degraded pasture is not necessarily degraded land while degraded soil is related to grazing degrades.
\end{abstract}

Key words: environmental degradation, geostatistics, soil-plant interface, grazing management 


\section{INTRODUÇÃO}

Nos países em desenvolvimento as demandas de forragem para a pecuária de corte e leite excedem, durante parte do ano, a produção sustentável das pastagens além da falta de ajuste de lotação promover seu uso predatório o ano todo, o que causa degradação do pasto e alterações na qualidade do solo e na interface solo-planta-animal. Comumente, o processo de degradação do solo decorre do seu uso incorreto, resultado do desmatamento, queimada, negligência no manejo da pastagem, compactação e erosão (Cunha et al., 2008). Apesar dos indicadores há lacunas no saber de como a degradação do pasto é refletida sob o solo (Virágh et al., 2011) principalmente nas regiões de fronteira pecuária.

Segundo Araújo et al. (2007), algumas características relativamente simples podem ser usadas para avaliar a qualidade do solo de forma bastante eficaz. Os parâmetros escolhidos para tal ponderação devem abranger atributos biológicos, químicos e físicos. Dentre os principais, de caráter prático, podem ser destacadas a matéria orgânica, a capacidade de troca catiônica e a resistência à penetração. As avaliações conjuntas dessas propriedades podem ajudar a identificar o grau de alteração da qualidade do solo.

Outro ponto relevante é que a determinação das mudanças ocorridas no solo deve ser realizada por conferição das áreas sob ação antrópica com ambientes inalterados, como no caso das florestas por representarem as condições ecológicas de estabilidade do ambiente. Neste sentido, a ferramenta da geoestatística pode ser empregada para diagnosticar, em áreas com diferentes usos, as principais alterações ocorridas tomandose por base um ambiente virgem. O monitoramento com auxílio desta ferramenta pode identificar formas de manejo que mais preservem o solo, bem como aquelas nocivas à vitalidade da pecuária extensiva nacional (Islam \& Weil, 2000).

É de fundamental importância relacionar a degradação do pasto com a do solo por métodos de aplicação rápida e prática. A avaliação de pastos em diferentes graus de degradação relacionados aos atributos do solo, é útil na identificação de parâmetros que devam apresentar maior expressão nos modelos quantificadores da degradação ambiental. A identificação desses elos entre o definhamento da pastagem e a perda de qualidade do solo pode ajudar na eficiência da tomada de decisão de ações de curto, médio e longo prazo (Virágh et al., 2011).

O objetivo com a realização deste estudo foi diagnosticar as alterações no solo em pastagens com o aumento do grau de degradação do pasto, determinar se a degradação do pasto implica na degradação do solo e eleger os atributos do solo mais relacionados com a degradação.

\section{Material e Métodos}

A área de estudo está situada nas imediações da Escola de Medicina Veterinária e Zootecnia da Universidade Federal do Tocantins - UFT do campus de Araguaína, TO, localizado nas coordenadas $07^{\circ} 12^{\prime} 28^{\prime \prime}$ Sul e $48^{\circ} 12^{\prime} 26^{\prime \prime}$ Oeste. A vegetação é caracterizada pelo ecótono floresta Amazônia/Cerrado. A altitude média é de $240 \mathrm{~m}$ e o clima da região, segundo a classificação de Köppen, é AW - Tropical de verão úmido com estação seca e chuvosa bem definida e precipitação média anual de $1800 \mathrm{~mm}$. A região apresenta temperaturas máximas de $40^{\circ} \mathrm{C}$ e mínimas de $18^{\circ} \mathrm{C}$ com umidade relativa do ar média anual de $76 \%$.

Conforme metodologia da EMBRAPA(2006) o solo da área foi classificado como Neossolo Quartzarênico Órtico típico, com textura arenosa. Os atributos do solo foram avaliados em oito diferentes estratos vegetais, caracterizados pela quantidade e características vegetais, todas com declividade menor que $5 \%$. As diferentes áreas estudadas são adjacentes, sendo os locais de coleta georreferenciados e o mesmo padrão de distribuição de amostragem das variáveis nas áreas. Os pontos para amostragem de solo apresentavam característica vegetal homogênea dentro de cada estrato, em um raio de cinco metros.

As áreas amostradas foram caracterizadas e delimitadas de acordo com seu estado de cobertura vegetal, como proposto por Araújo et al. (2007), para avaliar as condições do solo em função do estado da vegetação existente, como segue:

Floresta Amazônia/Cerrado nativo ( $\mathrm{ACN}$ ): área sob vegetação de ecótono Amazônia/Cerrado preservada e sem histórico de ação antrópica - escolhida como referência para comparação das alterações dos atributos químicos e físicos do solo (A6);

Capoeira (CP): área com interferência antrópica anterior há dez anos e se encontra em estado de restauração natural da vegetação há pelo menos cinco anos (A8);

Pastagem cultivada (PC): área que passou por substituição da vegetação natural por pastagem de Brachiaria brizantha $\mathrm{cv}$. Marandu, sendo utilizada há cerca de dez anos como pasto para bovinos, sem controle de lotação e com controle mecânico de pragas - área com maior atividade de pastejo (A7);

Pastagem cultivada em pousio (PCP): área que passou por substituição da vegetação natural por pastagem de $B$. brizantha cv. Marandu, sendo utilizada há cerca de dez anos como pasto para bovinos sem controle de lotação e com controle mecânico de pragas; estava em pousio há cerca de um ano (A5);

Pastagem extremamente degradada (PED): área que passou por substituição da vegetação natural por pastagem de $B$. brizantha $\mathrm{cv}$. Marandu, sendo utilizada há cerca de quinze anos como pasto para bovinos sem controle de lotação e de pragas. Grande proporção de plantas invasoras (100\%), sem sinais da pastagem cultivada e com áreas de solo descoberto (A4);

Pastagem fortemente degradada (PFD): área que passou por substituição da vegetação natural por pastagem de Brachiaria brizantha cv. Marandu, sendo utilizada há cerca de dez anos como pasto para bovinos sem controle de lotação e com controle mecânico de pragas. Alta infestação por plantas invasoras e baixa produção de biomassa da pastagem. Poucas áreas com solo descoberto e presença de espécies arbóreas (A3);

Pastagem degradada (PD): área que passou por substituição da vegetação natural por pastagem de $B$. brizanth $\mathrm{cv}$. Marandu, sendo utilizada há cerca de dez anos como pasto para bovinos sem controle de lotação e com controle mecânico de pragas. Moderadamente infestada por plantas invasoras e com pastagem definhando (maior cobertura pela forrageira que a área 3). Poucas áreas com solo descoberto (A1);

Pastagem Moderadamente Degradada (PMD): área que passou por substituição da vegetação natural por pastagem 
de $B$. brizantha cv. Marandu, sendo utilizada há cerca de dez anos como pasto para bovinos sem controle de lotação e com controle mecânico de pragas. Pouco infestada por invasoras, com poucas áreas com solo descoberto e pastagem com baixa taxa de rebrota (maior cobertura pela forrageira que a área 1). Presença de espécies arbóreas (maior quantidade que a área 3) (A2);

As principais espécies tidas como invasoras foram: Malva roxa (Urenalobata) Assa peixe (Vernonia polyanthes), Mata campo (Vernonia ferruginea Less) e Pindoba (Orrbignya speciosa). A principal espécie tida como arbórea na pastagem, foi o Babaçu (Orrbignya speciosa) que, de acordo com o histórico das áreas, nunca teve correção e/ou adubação de reposição ao longo dos anos de uso. O mapa da área total com suas divisões internas em função das peculiaridades da cobertura vegetal e os pontos de amostragem das variáveis do solo e produção de forragem e plantas invasoras podem ser visualizados na Figura 1.

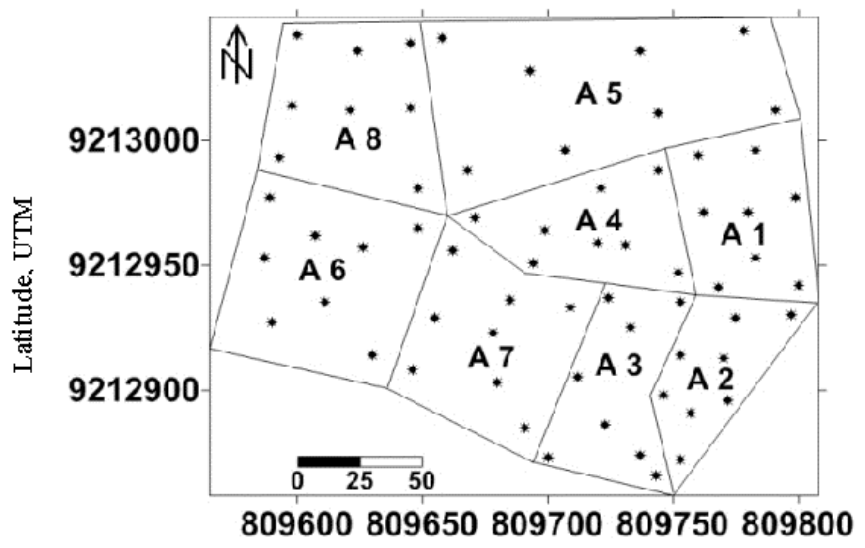

Longitude, UTM

* - Ponto de coleta de informações químicas e física do solo e de biomassa vegetativa

Figura 1. Mapa da área total avaliada com diferentes coberturas vegetais e estado de conservação. Pastagem degradada (A1), Pastagem moderadamente degradada (A2), Pastagem fortemente degradada (A3), Pastagem extremamente degradada (A4), Pastagem cultivada em pousio (A5), Amazônia/Cerrado nativo (A6), Pastagem cultivada (A7) e Capoeira (A8)

Como indicador quantificado da qualidade física do solo foi determinada a resistência mecânica do solo a penetração (RP). A RP foi determinada com o uso de penetrômetro de anel dinamométrico ou estático (modelo Solotest 1.210.001). O valor obtido no relógio de leitura foi transformado em kgf pela equação de calibração do aparelho: $\mathrm{R}(\mathrm{kgf})=1,0444+0,2998 \mathrm{y}$; em que $\mathrm{R}$ é a resistência à penetração em $\mathrm{kgf}((\mathrm{kgf}$ por área do cone)* $0,098=\mathrm{MPa}$ ) e y é a leitura no relógio $(\mathrm{mm})$ (Roque et al., 2003). As mensurações foram realizadas nas camadas de 0-5 e 5-10 cm de profundidade constando de cinco medições na área, em torno de cada coleta de solo (raio de $1 \mathrm{~m}$ ).

As coletas de solo dentro de cada gleba foram distribuídas aleatoriamente. A amostra do solo em cada ponto constou de uma amostra composta por cinco amostras simples, nas camadas de $0-5$ e $5-10 \mathrm{~cm}$ de profundidade. Foram realizadas as seguintes avaliações químicas: fósforo $(\mathrm{P})$ e potássio
$\left(\mathrm{K}^{+}\right)$extraíveis em Melich-1 $\left(\mathrm{mg} \mathrm{dm}{ }^{-3}\right)$, matéria orgânica (M.O.) $\left(\mathrm{g} \mathrm{dm}^{-3}\right), \mathrm{pH}\left(\mathrm{CaCl}_{2}\right)$, cálcio $\left(\mathrm{Ca}^{2+}\right)$, magnésio $\left(\mathrm{Mg}^{2+}\right)$ e alumínio $\left(\mathrm{Al}^{3+}\right)$ trocáveis e acidez potencial $(\mathrm{H}+\mathrm{Al})$. Com os valores obtidos nas análises do solo foram calculadas a saturação por bases (V\%) e a saturação por alumínio $(\mathrm{m} \%)$. As análises foram conduzidas no Laboratório de Solo do curso de Zootecnia da UFT, de acordo com as recomendações da EMBRAPA (2009).

Em todas as áreas, com exceção da mata nativa, foram procedidas amostras de biomassa vegetal. Esta amostragem foi realizada de modo aleatório e representativo em um ponto de característica intermediária ao ambiente próximo (raio de $5 \mathrm{~m}$ ). O material colhido consistia da pastagem e das plantas invasoras, quando essas espécies estavam presentes. O procedimento de coleta foi com auxílio de moldura de $1 \mathrm{~m}^{2}$, cujo material foi cortado rente ao solo. As coletas foram conduzidas em pontos adjacentes à coleta do solo. No material obtido foi feita a separação de gramínea forrageira e plantas invasoras e determinadas as quantidades com base da matéria seca (MS) sendo a resposta apresentada em g de MS $\mathrm{m}^{-2}$ de gramínea ou invasora. O total de amostras em toda a área, para caracterização da vegetação e do solo em cada profundidade, foi de 64 , sendo suficiente para interpolação dos dados (Landim, 2006). As coletas foram distribuídas em malha irregular dentro de cada área característica, sendo oito amostras por área estudada de modo a se buscar representatividade do ambiente (Figura 1).

A estatística descritiva foi aplicada para analisar os valores de médias, mediana, variância e os coeficientes de variação, assimetria e curtose, pelo uso de software estatístico. Os valores observados para os indicadores da qualidade do solo na área com floresta nativa foram utilizados como referência visto que se trata de ecossistema em equilíbrio e estável. A diminuição das características químicas do solo em relação à área preservada indica redução da qualidade. No caso de ocorrer aumento do valor da característica avaliada, como a RP, em relação ao sistema natural, esta variação positiva foi considerada como aumento de perda da qualidade. Por exemplo, se o valor de RP para o solo da área de referência foi de $0,5 \mathrm{MPa}$ e para determinada área de uso em avaliação foi de $1 \mathrm{MPa}$, significa que houve redução de $50 \%$ na qualidade para esse indicador (Araújo et al., 2007).

A variabilidade das características do solo em toda área em estudo foi avaliada pelo uso da geoestatística. Os atributos químicos, físico e a produção de biomassa após análise exploratória, foram submetidos à hipótese de normalidade, examinada pelo teste de Kolmogorov-Smirnov (0,05 de probabilidade). A dependência espacial foi analisada por meio de ajustes de semivariogramas com base na pressuposição de estacionariedade da hipótese intrínseca (Vieira, 2000).

A dependência espacial entre as observações e a autocorrelação entre locais vizinhos foi calculada através do semivariograma (Matheron, 1963) conforme Eq. 1.

$$
\gamma(h)=\frac{1}{2 N(h)} \sum_{i=1}^{N(h)}\left[Z\left(x_{i}\right)-Z\left(x_{i}+h\right)\right]^{2}
$$


em que :

$\mathrm{N}(\mathrm{h})$ - o número de pares de valores medidos $\mathrm{Z}\left(\mathrm{x}_{\mathrm{i}}\right), \mathrm{Z}\left(\mathrm{x}_{\mathrm{i}}+\mathrm{h}\right)$, separados pela distância $h$. O gráfico de $\gamma^{*}(\mathrm{~h})$ versus os valores correspondentes de $\mathrm{h}$, é uma função do vetor $\mathrm{h}$ e, portanto, depende de ambos, magnitude e direção de $h$.

Modelos matemáticos - esférico, exponencial e gaussiano - foram ajustados aos semivariogramas. O ajuste dos modelos teóricos aos semivariogramas experimentais foi realizado no programa GS+ pelo método de tentativa e erro e pelo exame dos resultados da validação cruzada (Vieira, 2000) sendo a seleção do modelo ajustado realizada com base na minimização da soma dos quadrados dos resíduos (SQR) e no maior coeficiente de determinação $\left(\mathrm{R}^{2}\right)$.

A partir do ajuste do modelo matemático aos dados foram definidos os parâmetros do semivariograma: o efeito pepita $\left(\mathrm{C}_{0}\right)$, que é o valor de $\gamma$ quando $\mathrm{h}=0$; o alcance da dependência espacial (A), que é a distância em que $\gamma(\mathrm{h})$ permanece constante após aumentar com o incremento de $\mathrm{h}$ e o patamar $\left(\mathrm{C}_{0}+\mathrm{C}\right)$, que é o valor de $\gamma(\mathrm{h})$ a partir do alcance e que se aproxima da variância dos dados, se ela existir (Landim, 2006).

Para análise do grau de dependência espacial (GDE) foi utilizada a proporção dada pela Eq. 2:

$$
\mathrm{GDE}=\left[\frac{\mathrm{C}}{\mathrm{C}+\mathrm{C}_{0}}\right] 100
$$

que permite classificar o GDE em dependência espacial fraca (GDE $\leq 25 \%)$, dependência espacial moderada $(25 \%<\mathrm{GDE} \leq$ $75 \%$ ) e dependência espacial forte (GDE $>75 \%$ ) (Cambardella et al., 1994).

O resultado do trabalho foi expresso em forma de mapas de isolinhas e a maneira de localizar uma isolinha entre dois pontos foi determinada pela interpolação dos dados, por meio de Krigagem ordinária (Landim, 2006). O programa Surfer 8.0 foi utilizado para manipulação e visualização da distribuição espacial, através da construção dos mapas de isolinhas das variáveis de acordo com as coordenadas geográficas. A análise e os mapas foram feitos tratando-se a área de levantada como um todo, sem a divisão em piquetes. A divisão visualizada no mapa serve para orientação e distinção das áreas.

\section{Resultados e Discussão}

Os resultados da análise descritiva dos atributos do solo nos diferentes estrados vegetais e profundidades estudadas estão apresentados na Tabela 1. Todas as variáveis analisadas em ambas as profundidades apresentaram valores de assimetria positivos, com mediana menor que a média, com exceção do $\mathrm{pH}$ na profundidade de $5-10 \mathrm{~cm}$. Os valores de assimetria positiva demonstram haver tendência de concentração dos valores abaixo da média observada, sendo tal tendência tanto mais expressiva quanto maior for o valor obtido; situação inversa se dá para valores negativos desse coeficiente. Com exceção do $\mathrm{pH}$ e V\% na profundidade de $0-5 \mathrm{~cm}$ e $\mathrm{P}$ e V\% na de 5-10 $\mathrm{cm}$ que apresentaram distribuição de frequência platicúrtica, ou seja, curtose negativa, os demais parâmetros do solo tiveram distribuição de frequência leptocúrtica mostrando, assim, que a maioria dos atributos possui os dados próximos ao seu centro no gráfico de distribuição de frequência.

Mesmo os coeficientes de assimetria e curtose demonstrando que os atributos do solo têm distribuições assimétricas e alguns atributos apresentarem distribuição de frequência com desvios mais elevados para ambos os coeficientes em relação à distribuição normal, os valores da média e mediana das variáveis estudadas se mostraram similares. Indicando que os conjuntos de dados não apresentam assimetria acentuada e também possuem ou se aproximam da distribuição normal. Podendo isto ser indicativo de que as medidas de tendência central não são dominadas por valores atípicos na distribuição (Cambardella et al., 1994).

A normalidade ou não das variáveis indicou que apenas $\mathrm{pH}$ e V\% apresentaram distribuição normal em ambas as profundidades estudadas sendo que, além dessas variáveis, somente a M.O. sinalizou distribuição normal na profundidade de 0-5 cm. Carvalho et al. (2002) utilizaram a Geoestatística na determinação da variabilidade espacial de características

Tabela 1. Estatística descritiva dos atributos do solo nos diferentes níveis de coberturas do capim Marandu nas profundidades de $0-5$ e $5-10 \mathrm{~cm}$

\begin{tabular}{|c|c|c|c|c|c|c|c|}
\hline \multirow{2}{*}{ Variável } & \multirow{2}{*}{ Média } & \multirow{2}{*}{ Mediana } & \multirow{2}{*}{ Variância } & \multicolumn{3}{|c|}{ Coeficiente } & \multirow{2}{*}{$\mathbf{K S}^{1}$} \\
\hline & & & & Variação & Assimetria & Curtose & \\
\hline & & & & $0-5 \mathrm{~cm}$ & & & \\
\hline M.O. $\left(\mathrm{g} \mathrm{dm}^{-3}\right)$ & 22,50 & 21,00 & 131,66 & 51,00 & 1,16 & 2,64 & $0,099^{*}$ \\
\hline $\mathrm{pH}\left(\mathrm{CaCl}_{2}\right)$ & 4,47 & 4,45 & 0,08 & 6,47 & 0,09 & $-0,88$ & $0,076^{*}$ \\
\hline $\mathrm{P}\left(\mathrm{mg} \mathrm{dm}^{-3}\right)$ & 1,04 & 1,01 & 0,01 & 10,54 & 2,01 & 4,75 & $0,194^{* *}$ \\
\hline V\% (\%) & 55,04 & 54,81 & 114,74 & 19,46 & 0,02 & $-0,06$ & $0,061^{*}$ \\
\hline$m \%(\%)$ & 10,31 & 7,05 & 60,46 & 75,40 & 1,63 & 3,21 & $0,225^{\star *}$ \\
\hline \multirow[t]{2}{*}{$\mathrm{RP}$ (MPa) } & 1,75 & 1,72 & 0,37 & 34,91 & 0,86 & 0,86 & $0,130^{* *}$ \\
\hline & & & & $5-10 \mathrm{~cm}$ & & & \\
\hline M.O. $\left(\mathrm{g} \mathrm{dm}^{-3}\right)$ & 19,00 & 15,88 & 219,70 & 77,84 & 3,58 & 15,92 & $0,231^{* *}$ \\
\hline $\mathrm{pH}\left(\mathrm{CaCl}_{2}\right)$ & 4,32 & 4,32 & 0,09 & 7,03 & 0,90 & 2,22 & $0,086^{*}$ \\
\hline $\mathrm{P}\left(\mathrm{mg} \mathrm{dm}^{-3}\right)$ & 0,96 & 0,95 & 0,07 & 7,09 & 1,00 & $-0,04$ & $0,177^{* *}$ \\
\hline V\% (\%) & 48,63 & 48,39 & 132,56 & 23,68 & 0,23 & $-0,32$ & $0,006^{\star}$ \\
\hline $\mathrm{m} \%(\%)$ & 22,96 & 18,30 & 332,96 & 79,47 & 1,75 & 3,60 & $0,169^{* *}$ \\
\hline $\mathrm{RP}(\mathrm{MPa})$ & 1,63 & 1,56 & 0,26 & 31,37 & 1,49 & 2,08 & $0,229^{* *}$ \\
\hline
\end{tabular}

(1)KS - teste de normalidade de Kolmogorov-Smirnov; ${ }^{\left({ }^{*}\right)}$ : significativo a 0,05; ${ }^{(*)}$ : não-significativo a 0,05 da probabilidade; M0 - Matéria orgânica; P - Fósforo disponível; V\% - Saturação por bases; m\% - Saturação por alumínio; RP - Resistência a penetração 
químicas do solo sob diferentes preparos, constatando que $40 \%$ das 30 combinações possíveis apresentaram valores de assimetria e curtose não compatíveis com a distribuição normal. Já Cavalcante et al. (2007) observaram, também avaliando a variabilidade espacial de características químicas em diferentes usos e manejos do solo, que apenas $27,5 \%$ das 40 combinações possíveis não apresentaram normalidade nas distribuição dos dados. A não normalidade de $58 \%$ das possíveis combinações pode ser justificada pela heterogeneidade das diferentes coberturas vegetais das áreas estudadas.

A utilização do método de Krigagem para estimação de valores em locais não amostrados das variáveis naturais, apresenta melhores resultados quando a normalidade dos dados é satisfeita (Paz-Gonzalez et al., 2001). No entanto, o estudo geoestatístico de um conjunto de dados não exige que esses tenham distribuição normal (Corá \& Beraldo, 2006); a normalidade deste conjunto de dados possibilita, porém, melhor ajuste do semivariograma, além de facilitar este processo (Machado et al., 2007) o que, segundo Isaaks \& Srivastava (1989) a ocorrência ou não do efeito proporcional, em que a média e a variabilidade dos dados são constantes na área estudada, é de maior relevância que a normalidade da frequência de distribuição dos dados. Assim, torna-se possível, através da análise exploratória dos dados admitir, em princípio, que os dados estão suficientemente simétricos para o estudo geoestatístico.

Em síntese, os resultados da análise da estatística descritiva dos atributos do solo nas diferentes profundidades estudadas (Tabela 1) demonstraram, em torno dos valores médios, que a camada de $5 \mathrm{~cm}$ de profundidade apresentou melhores índices que a camada subsuperficial; situação compreensível e desencadeada principalmente pelo maior teor de M.O. nesta camada pois se sabe que as substâncias húmicas provenientes da mineralização do material orgânico elevaram significativamente a capacidade de troca catiônica e, em consequência, maior reserva de nutrientes minerais, o que é visível com a elevação do valor de $\mathrm{V} \%$ e a consequente diminuição do $\mathrm{pH}$ e $\mathrm{m} \%$.

De acordo com a classificação do coeficiente de variação (CV) proposta por Warrick \& Nielsen (1980), com exceção do $\mathrm{pH}$ e do $\mathrm{P}$ que apresentaram baixo $\mathrm{CV}(<12 \%)$ nas profundidades de $0-5$ e $5-10 \mathrm{~cm}$, da $\mathrm{m} \%$ em ambas as profundidades e da M.O. na profundidade de $5-10 \mathrm{~cm}$ que obtiveram CV alto $(>60 \%)$, todos os outros atributos do solo tiveram CV médio (12 a 60\%). O CV deve ser utilizado como parâmetro para validar os valores médios encontrados uma vez que, segundo Vanni (1998), coeficiente de variação acima de $35 \%$ revela que a média tem pouco significado e valores maiores que $65 \%$ refletem série de dados muito heterogênea anulando a confiabilidade da média.

$\mathrm{O}$ baixo $\mathrm{CV}$ observado para o $\mathrm{pH}$ corrobora com os resultados encontrados por Cavalcante et al. (2007), Machado et al. (2007) e Souza et al. (2008); entretanto, contrasta com o resultado encontrado para o CV do $\mathrm{P}$. O valor do $\mathrm{CV}$ do $\mathrm{pH}$ pode ser atribuído ao fato desta variável ser mensurada em uma escala pequena de valores e ser uma função logarítmica e o do $\mathrm{P}$ a sua baixa mobilidade no solo. Os valores médios e alto de $\mathrm{CV}$ dos demais atributos químicos do solo concordam com os resultados encontrados por Lima et al. (2010) e Silva Neto et al. (2011) e os de RP com Souza et al. (2006), resultados esses propiciados por se tratar de estudo de áreas distintas, quanto à sua cobertura vegetal, ao manejo e nível de degradação o que influencia, dentre outros processos, a decomposição de restos culturais e da serapilheira dos estratos arbóreos provocando, assim, alta variabilidade nos atributos do solo.

Referidos resultados do CV indicam que a utilização de valores médios não caracteriza adequadamente a variabilidade dos atributos do solo em áreas de pastagens em diferentes níveis de degradação acarretando, portanto, erros na distinção da área devido ao uso desses valores médios com alta variabilidade. Tais condições podem levar à sub ou superestimativa desses atributos.

Considerando os resultados e os valores médios dos atributos do solo, constata-se que a acentuada diminuição da produtividade agrícola promovida pelo processo de degradação das áreas de pastagens, não foi desencadeada unicamente pelos atributos do solo pois, mesmo apresentando $\mathrm{pH}$ com acidez elevada e $\mathrm{P}$ com concentração muito baixa, obteve valores médios de M.O. e V\%, além de m\% muito baixa (CFSMG, 1999) e valores de RP abaixo do considerado crítico ao desenvolvimento radicular (Sene et al., 1985). As práticas inadequadas de pastejo atreladas à falta de reposição de nutrientes, são apontadas como causas constantes do estabelecimento do processo de degradação de áreas de pastagens (Cunha et al., 2008).

As alterações dos atributos do solo promovidas pelos sistemas estudados e pela alta variabilidade dos dados de acordo com os CVs encontrados (Tabela 1) sugerem que, com as informações a respeito da variabilidade espacial, as variáveis devem ser incorporadas por meio de estudos de autocorrelação espacial (Kravchenko et al., 2006), o que ajudaria a reduzir o erro padrão das estimativas médias (Cerri et al., 2004).

Na profundidade de $0-5 \mathrm{~cm}$ os atributos do solo se ajustaram melhor ao modelo exponencial para $\mathrm{pH}$ e $\mathrm{V} \%$; esférico para M.O. e RP e gaussiano para $\mathrm{Pe} \mathrm{m} \%$. Em relação à profundidade de 5-10 cm, a MO, V\% e RP se ajustaram melhor ao modelo esférico enquanto o $\mathrm{pH}, \mathrm{P}$ e o $\mathrm{m} \%$ tiveram melhor ajuste ao modelo gaussiano (Tabela 2). Das 12 combinações possíveis os modelos teóricos que melhor se adequaram aos dados, foram o esférico e o gaussiano, seguidos do exponencial o que corrobora, em parte, com o descrito e encontrado na literatura, indicando os modelos teóricos esféricos e exponenciais como os mais comuns aos atributos do solo (Cambardella et al., 1994; Lima et al., 2010).

As relações entre o efeito pepita $\left(\mathrm{C}_{0}\right)$ e o patamar $\left(\mathrm{C}_{0}+\mathrm{C}\right)$ demonstram predominância de GDE moderada seguida de forte, tendo somente a $\mathrm{V} \%$ na profundidade de $0-5 \mathrm{~cm}$ GDE fraco. Segundo Cambardella et al. (1994) o forte GDE dos atributos do solo está relacionado a fatores intrínsecos como clima, relevo e material de origem enquanto o GDE moderado aos fatores extrínsecos, os quais são promovidos pela ação antrópica. Quanto maior a dependência espacial da variável melhor estrutura espacial e maior precisão podem ser obtidas na estimativa em locais não amostrados por intermédio de técnicas geoestatística como a Krigagem (Kravchenko et al., 2006; Lima et al., 2010).

$\mathrm{Na}$ análise dos resultados dos semivariogramas ajustados para os atributos do solo (Tabela 2) há duas medidas de grande 
Tabela 2. Modelos e parâmetros estimados dos semivariogramas ajustados aos valores dos atributos do solo nas diferentes coberturas vegetais nas profundidades de 0-5 e 5-10 cm

\begin{tabular}{|c|c|c|c|c|c|c|c|c|}
\hline \multirow{2}{*}{ Atributo } & \multicolumn{8}{|c|}{ Parâmetro } \\
\hline & Modelo & $\mathrm{C}_{0}{ }^{1}$ & $C_{0}+C^{2}$ & $A^{3}(m)$ & $\mathrm{GDE}^{4}(\%)$ & Classe & $\mathbf{R}^{2^{*}}$ & $\mathrm{SQR}^{5}$ \\
\hline & \multicolumn{8}{|c|}{$0-5 \mathrm{~cm}$} \\
\hline M.O. $\left(\mathrm{g} \mathrm{dm}^{-3}\right)$ & Esférico & 80 & 155,0 & 88 & 48 & Mod. & 0,38 & 2765 \\
\hline $\mathrm{pH}\left(\mathrm{CaCl}_{2}\right)$ & Exponencial & 0,0442 & 0,0939 & 43,30 & 53 & Mod. & 0,70 & $4,954 \times 10^{-04}$ \\
\hline $\mathrm{P}\left(\mathrm{mg} \mathrm{dm}^{-3}\right)$ & Gaussiano & 0,0054 & 0,027 & 159,90 & 80 & Forte & 0,92 & $1,639 \times 10^{-05}$ \\
\hline V\% (\%) & Exponencial & 87,38 & 122,78 & 135,17 & 29 & Mod. & 0,52 & 523 \\
\hline $\mathrm{m} \%(\%)$ & Gaussiano & 32,4 & 77,06 & 131,29 & 58 & Mod. & 0,94 & 147 \\
\hline \multirow[t]{2}{*}{$\mathrm{RP}(\mathrm{MPa})$} & Esférico & 0,072 & 0,458 & 111,80 & 84 & Forte & 0,88 & 0,0146 \\
\hline & \multicolumn{8}{|c|}{$5-10 \mathrm{~cm}$} \\
\hline M.O. $\left(\mathrm{g} \mathrm{dm}^{-3}\right)$ & Esférico & 0 & 250,0 & 53 & 100 & Forte & 0,69 & 1680 \\
\hline $\mathrm{pH}\left(\mathrm{CaCl}_{2}\right)$ & Gaussiano & 0,0753 & 0,3026 & 375,90 & 75 & Mod. & 0,54 & $1,107 \times 10^{-03}$ \\
\hline $\mathrm{P}\left(\mathrm{mg} \mathrm{dm}^{-3}\right)$ & Gaussiano & 0,0021 & 0,009 & 145 & 76 & Forte & 0,90 & $2,814 \times 10^{-06}$ \\
\hline V\% (\%) & Esférico & 119,94 & 145,55 & 164,10 & 18 & Fraco & 0,30 & 1584 \\
\hline $\mathrm{m} \%(\%)$ & Gaussiano & 150 & 568,3 & 206,11 & 74 & Mod. & 0,99 & 1258 \\
\hline $\mathrm{RP}(\mathrm{MPa})$ & Esférico & 0,1048 & 0,3076 & 91,90 & 66 & Mod. & 0,52 & 0,0251 \\
\hline
\end{tabular}

${ }^{(1)} \mathrm{C}_{0}$ : efeito pepita; ${ }^{(2)} \mathrm{C}_{0}+\mathrm{C}$ : patamar; ${ }^{(3)} \mathrm{A}$ : alcance; ( ${ }^{(4)} \mathrm{GDE}$ : grau de dependência espacial; ${ }^{(5)} \mathrm{SQR}$ : Soma do quadrado dos resíduos; ${ }^{(*)} \mathrm{R}^{2}$ : coeficiente de determinação; M.O.: Matéria orgânica; $\mathrm{P}$ : Fósforo disponível; V\%: Saturação por bases; m\%: Saturação por alumínio; RP: Resistência a penetração; Mod.: Grau de dependência espacial moderado

importância. O alcance (A) que se refere ao raio máximo da influência de um ponto em que todos os pontos dentro deste circulo são correlacionados podendo ser usados para estimar valores para qualquer ponto entre eles. Segundo Corá \& Beraldo (2006) valores maiores de alcance promovem maior confiança nas estimativas feitas com interpolação por Krigagem ordinária, gerando mapas que melhor representam a realidade devido à influencia exercida sobre o número de valores usados na interpolação, além de auxiliar na determinação da amostragem da área (Carvalho et al., 2002; Souza et al., 2008). Entre as profundidades estudadas a M.O., o P e o RP apresentaram valores superiores de A na camada de 0-5 em relação à de 5-10 $\mathrm{cm}$, comportamento este explicado pela maior deposição de material orgânico provindo da cobertura vegetal e, em relação ao $\mathrm{P}$, sua baixa mobilidade no perfil do solo. A descontinuidade espacial dos outros atributos do solo na camada superficial esta relacionada à maior diversidade dentro das diferentes coberturas vegetais, na deposição do material orgânico, atividades biológicas e nas interações químicas. E o efeito pepita $\left(\mathrm{C}_{0}\right)$ o qual sua magnitude tem grande importância na Krigagem visto que, quanto maior for a diferença do $\mathrm{C}_{0}$ em relação ao patamar $\left(\mathrm{C}_{0}+\mathrm{C}\right)$ do semivariograma maior também a continuidade do fenômeno, menor a variância da estimativa ou maior a confiança que se pode ter na estimativa (Isaaks \& Srivastava, 1989).

A utilização da geoestatística na análise da produção de massa seca de forragem e plantas invasoras (Tabela 3) demonstrou que ambas as variáveis apresentam dependência espacial com modelos matemáticos dos semivariogramas ajustados ao modelo esférico, sendo este modelo teórico do semivariograma, juntamente com o exponencial, os mais comuns aos atributos de solo e plantas (Cambardella et al., 1994).
A massa seca de forragem e as plantas invasoras possuem relação entre $\mathrm{C}_{0}$ e $\mathrm{C}+\mathrm{C}_{0}$ de 77 e $50 \%$ respectivamente, o que classifica essas variáveis como tendo forte e moderado grau de dependência espacial (Cambardella et al., 1994). Em relação aos valores dos alcances encontrados há maior descontinuidade espacial da produção de forragem em relação à de plantas invasoras; tal resultado também observado por Dim et al. (2011) e é explicado pelos diferentes graus de degradação estudados sendo que, em todas as áreas, com exceção da mata, foi observada incidência de plantas invasoras, o que já não é verdade para a produção de forragem (Figura 2).

A partir dos modelos obtidos para os semivariogramas ajustados para cada atributo estudado, estimaram-se os valores das variáveis do solo e de massa seca em locais não amostrados por meio do método de interpolação geoestatístico de Krigagem ordinária. Deste modo foi possível, com os valores estimados, construir mapas de isolinhas permitindo visualizar arranjos de distribuição espacial dos atributos do solo e produção de biomassa de forragem e plantas invasoras bem distintos entre os diferentes extratos vegetais proporcionando a identificação de zonas de concentração das variáveis estudadas (Figuras 2 e 3 ).

As áreas com os diferentes níveis de degradação, pastagens degradadas (A1), moderadamente degradada (A2), fortemente degradada (A3) e extremamente degradada (A4), apresentaram redução na produção forrageira seguidas de incremento na biomassa de plantas invasoras (Figura 2). Este comportamento é bem característico de ambientes amazônicos em que o processo de degradação está relacionado à acentuada diminuição da produtividade agrícola que seria esperada para determinada área podendo ou não ter perdido a capacidade de manter a produtividade do ponto de vista biológico, passível de

Tabela 3. Modelos e parâmetros estimados dos semivariogramas ajustados aos valores de produção de massa seca de forragem e plantas invasoras nas diferentes coberturas vegetais

\begin{tabular}{|c|c|c|c|c|c|c|c|c|}
\hline \multirow{2}{*}{$\begin{array}{c}\text { Atributo } \\
\left(\mathrm{g} \mathrm{m}^{-2}\right)\end{array}$} & \multicolumn{8}{|c|}{ Parâmetro } \\
\hline & Modelo & $\mathrm{C}_{0}{ }^{1}$ & $C_{0}+C^{2}$ & $A^{3}(m)$ & $\operatorname{GDE}^{4}(\%)$ & Classe & $\mathbf{R}^{2^{*}}$ & $\mathbf{S Q R}^{5}$ \\
\hline Pl. dan. & Esférico & 45800 & 200900 & 410,9 & 77 & Forte & 0,82 & $1,245.10^{+09}$ \\
\hline M. For. & Esférico & 18530 & 37070 & 127,3 & 50 & Mod. & 0,78 & $7,264 \cdot 10^{+07}$ \\
\hline
\end{tabular}

${ }^{(1)} \mathrm{C}_{0}$ : efeito pepita; ${ }^{(2)} \mathrm{C}_{0}+\mathrm{C}$ : patamar; ${ }^{(3)} \mathrm{A}$ : alcance; ${ }^{(4)} \mathrm{GDE}$ : grau de dependência espacial; ${ }^{(5)} \mathrm{SQR}$ : Soma do quadrado dos resíduos; ${ }^{\left({ }^{*} \mathrm{R}\right.}$ : : coeficiente de determinação; PI. dan.: Massa de plantas invasoras; M. For:: Massa de forragem; Mod.: Grau de dependência espacial moderado 

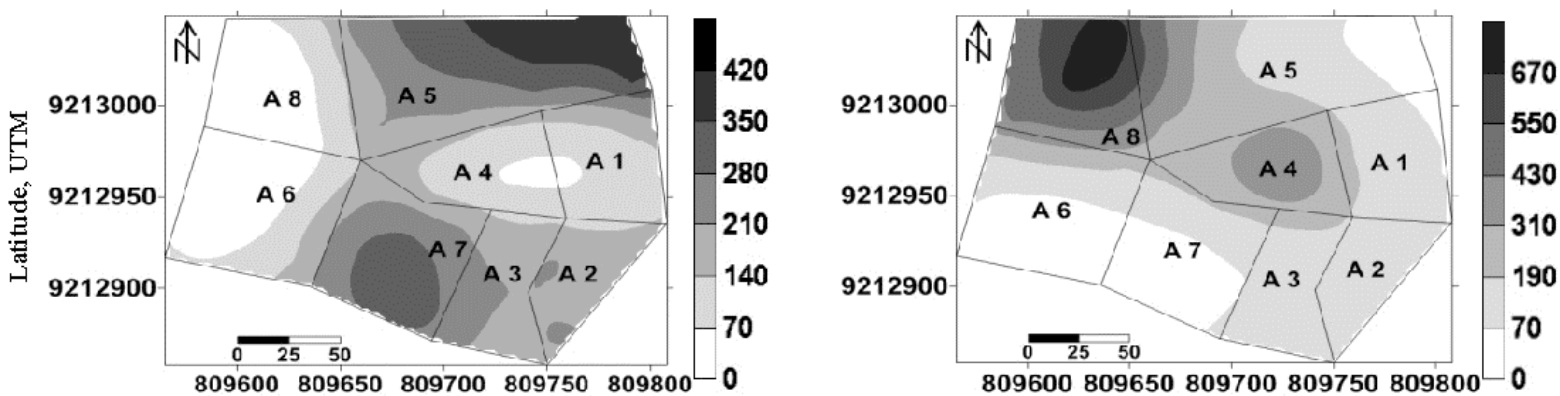

Longitude, UTM

(A1) pastagem degradada, (A2) pastagem moderadamente degradada, (A3) pastagem fortemente degradada, (A4) pastagem extremamente degrada, (A5) pastagem cultivada em pousio (A6) Amazônia/Cerrado nativo, (A7) pastagem cultivada e (A8) capoeira

Figura 2. Mapas de isolinhas da distribuição espacial da produção de massa seca de forragem (A) e de plantas invasoras (B) em $\mathrm{g} \mathrm{m}^{2}$, em função das diferentes coberturas vegetais

acarretar a diminuição da produção da forrageira dominante e a mudança na composição botânica com aumento na invasão de novas espécies (Dias Filho, 2006); fato este bem representado nos mapas de produção de massa seca de forragem e plantas invasoras (Figura 2).

O processo de substituição de ambientes nativos por sistemas produtivos pode promover diversas modificações ambientais

A.

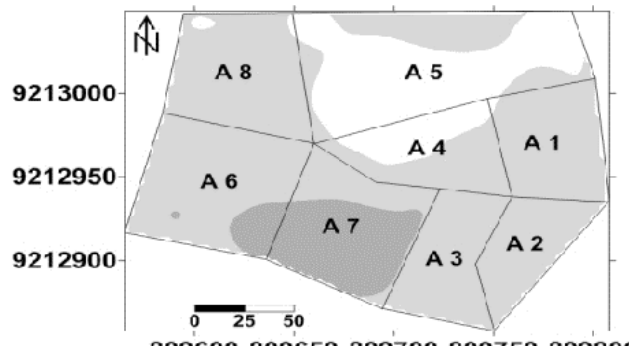

809600809650809700809750809800

C.

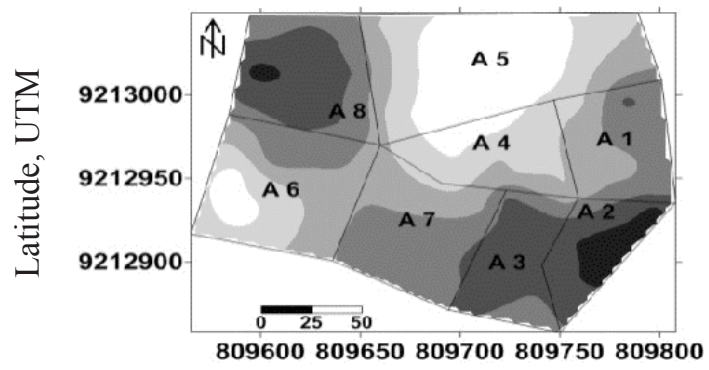

E.

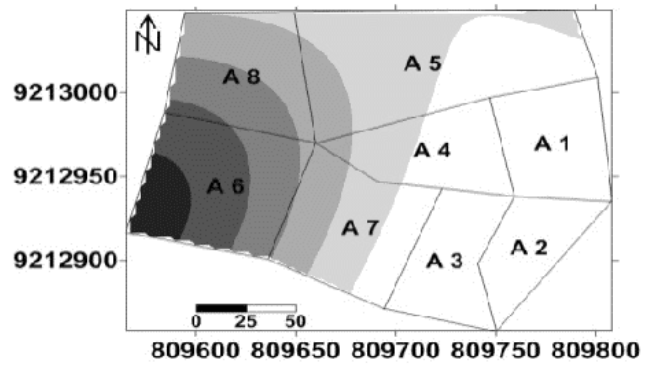

dentre elas a degradação do solo. Entretanto, o conhecimento das características e a propriedade do solo podem contribuir para o melhor manejo dessas áreas (Santos et al., 2010).

De acordo com a CFSMG (1999) na camada de $0-5 \mathrm{~cm}$ de profundidade (Figura 3) nas diferentes áreas analisadas, a M.O. obteve valores de muito baixo a bom; o $\mathrm{pH}$ indicou variação de acidez de muito elevada a elevada; o P, mesmo

B.

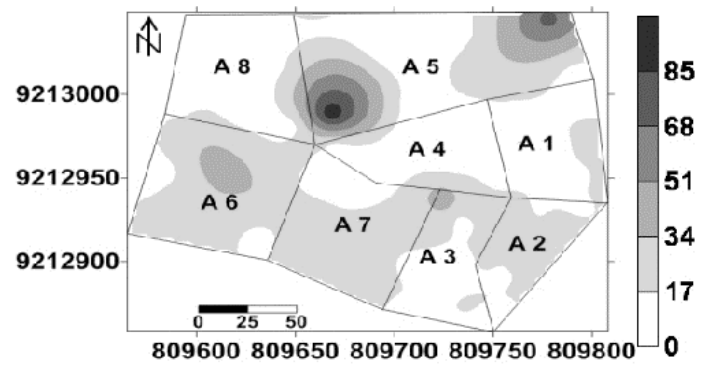

D.

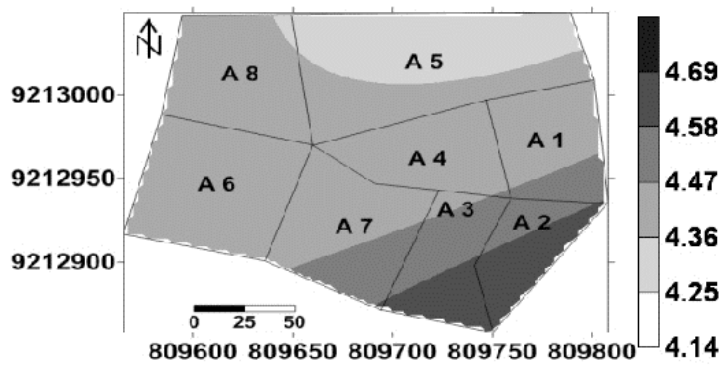

F.

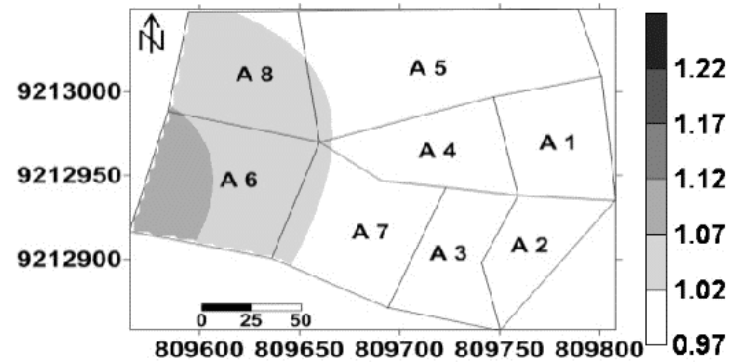

Longitude, UTM

Continua na próxima página... 
Continuação da Figura 3

G.

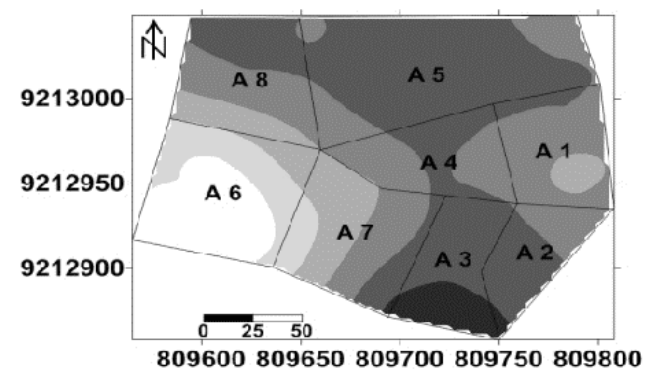

I.

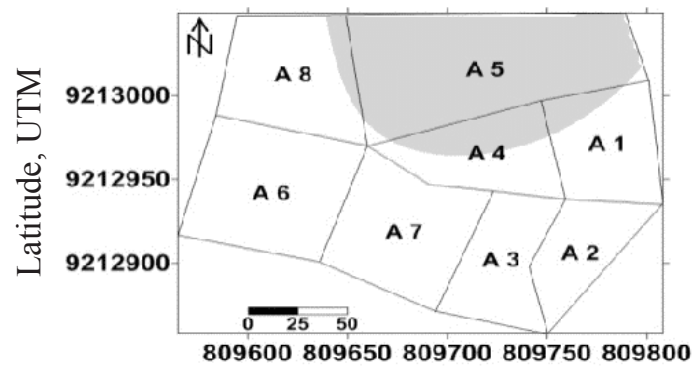

L.

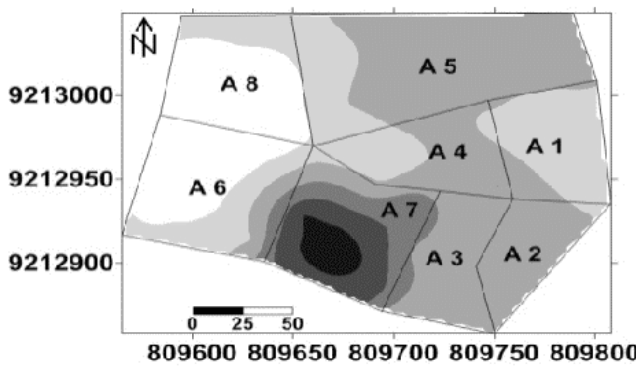

H.

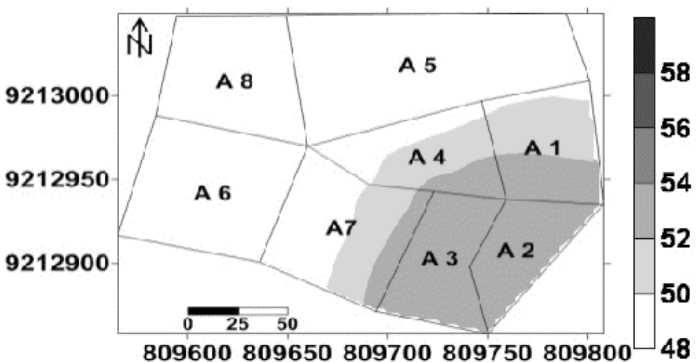

J.

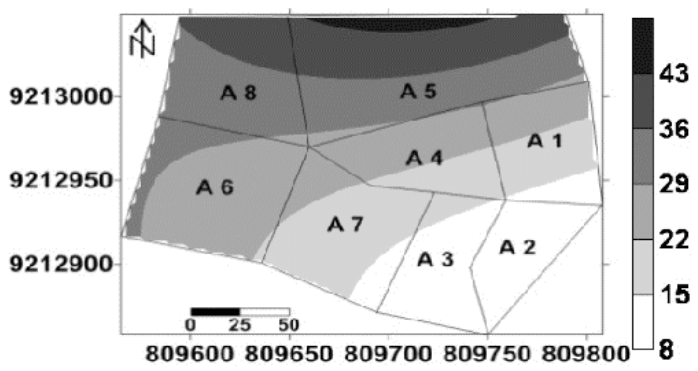

M.

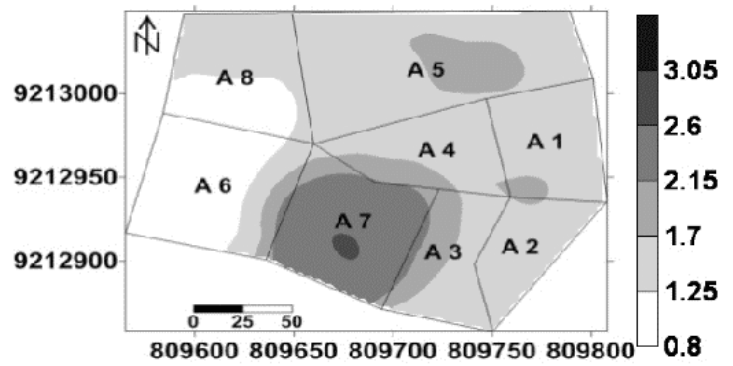

Longitude, UTM

Pastagem degradada (A1), pastagem moderadamente degradada (A2), pastagem fortemente degradada (A3), pastagem extremamente degrada (A4), pastagem cultivada em pousio (A5), Amazônia/Cerrado nativo (A6), pastagem cultivada (A7) e capoeira (A8)

Figura 3. Mapas de isolinhas da distribuição espacial dos atributos do solo, MO na profundidade 0-5 (A) e 5-10 $\mathrm{cm}\left(\mathrm{g} \mathrm{dm}^{-3}\right)(\mathrm{B}), \mathrm{pH}$ na profundidade de $0-5(\mathrm{C})$ e 5-10 $\mathrm{cm}\left(\mathrm{CaCl}_{2}\right)(\mathrm{D}), \mathrm{P}$ na profundidade de $0-5(\mathrm{E})$ e $5-10 \mathrm{~cm}$ $\left(\mathrm{mg} \mathrm{dm}^{-3}\right)(\mathrm{F}), \mathrm{V} \%$ na profundidade de $0-5(\mathrm{G})$ e $5-10 \mathrm{~cm}(\%)(\mathrm{H}), \mathrm{m} \%$ na profundidade de $0-5(\mathrm{I})$ e $5-10 \mathrm{~cm}(\%)$ (J), RP na profundidade de 0-5 (L) e 5-10 cm (MPa) em função das classes de uso do solo (M)

possuindo variação, obteve concentração muito baixa em todas as áreas; a V\%, valores médios e a $\mathrm{m} \%$ valores muito baixos a baixos; já a RP demonstra valores abaixo do considerado crítico ao desenvolvimento radicular no qual, segundo Sene et al. (1985) os valores críticos da correlação da resistência com o desenvolvimento das raízes para solos de textura arenosa se situam entre 6,0 a 7,0 $\mathrm{MPa}$.

Na profundidade de $5-10 \mathrm{~cm}$ (Figura 3) a M.O. sinalizou certa uniformização na sua distribuição, exceto por locais centralizados, variando de muito baixo a muito bom; o $\mathrm{pH}$ apresentou variação de acidez de muito elevada a elevada; o $\mathrm{P}$ obteve concentração muito baixa; a V\% valores médios e o m\% valores muito baixos a médios (CFSMG, 1999). A RP, do mesmo modo que na profundidade de $0-5 \mathrm{~cm}$, apresentou valores abaixo do considerado crítico ao desenvolvimento radicular (Sene et al., 1985).
Segundo Santos et al. (2010) o processo de degradação do solo é dinâmico e pode ser avaliado de diversas maneiras, dentre as quais a diminuição do teor de matéria orgânica do solo. Acoplado à perda da matéria orgânica ocorre, consequentemente, a perda dos nutrientes nela contidos. Entretanto, quando se avalia o processo de degradação do sistema solo-planta em âmbito amazônico este acaba de promover o aumento na proporção de plantas invasoras e consequente diminuição da gramínea forrageira o que necessariamente não deteriora as propriedades físico-químicas do solo podendo até, em certos casos, promover melhorias devido ao aumento da cobertura arbóreo-arbustiva (Dias Filho, 2006). O teor de MO e resistência à penetração nas áreas de pastagem com algum grau de degradação, apresentaram redução e elevação, respectivamente, quando comparadas com a área de vegetação nativa; também se observa a recuperação 
dessas características na área de capoeira, a qual se encontra em estado de restauração natural da vegetação.

O estudo mostrou a eficiência e a viabilidade da utilização do mapeamento da variabilidade espacial no sistema solo-planta permitindo a construção dos mapas de isolinhas, ferramenta esta que pode auxiliar na tomada de decisão promovendo, além de um manejo mais eficaz e racional por meio de aplicações de volumes herbicidas e de fertilizantes localizadas em função da real situação da pastagem, a maximização da produção forrageira e a conservação ambiental.

\section{CONCLUSÕES}

1. Os atributos do solo são influenciados pela ação antrópica tendo as áreas de pastagem com algum grau de degradação apresentado alterações qualitativas quando comparadas com a área de vegetação nativa.

2. A matéria orgânica do solo e a resistência à penetração mecânica podem ser utilizadas como parâmetros na identificação de áreas em declínio de produção de Brachiaria brizantha cv. Marandu em área de ecótono Amazônia/Cerrado.

3. A degradação biológica da pastagem promove, embora não necessariamente, a degradação dos atributos da qualidade do solo. O estado de restauração natural da vegetação tende a promover a recuperação dos atributos do solo afetados pela degradação das pastagens.

\section{Agradecimentos}

Ao CNPq (PQ 10/2009 - Produtividade em Pesquisa Processo 306943/2009-3) e à CAPES, pela concessão das bolsas de estudo.

\section{Literatura Citada}

Araújo, R.; Goedert, W. J.; Lacerda, M. P. C. Qualidade de um solo sob diferentes usos e sob cerrado nativo. Revista Brasileira de Ciência do Solo, v.31, p.1099-1108, 2007.

Cambardella, C. A.; Moorman, T. B.; Novak, J. M.; Parkin, T. B.; Karlen, D. L.; Turco, R. F.; Konopka, A. E. Field-scale variability of soil properties in Central Iowa Soils. Soil Science Society of America Journal, v.58, p.1501-1511, 1994.

Carvalho, J. R. P.; Silveira, P. M.; Vieira, S. R. Geoestatística na determinação da variabilidade espacial de características químicas do solo sob diferentes preparos. Pesquisa Agropecuária Brasileira, v.37, p.1151-1159, 2002.

Cavalcante, E. G. S.; Alves, M. C.; Souza, Z. M.; Pereira, G. T. Variabilidade espacial de atributos químicos do Solo sob diferentes usos e manejos. Revista Brasileira de Ciência do Solo, v.31, p.1329-1339, 2007.

Cerri, C. E. P.; Cerri, C. C.; Paustian, K.; Bernoux, M.; Mellilo, J. M. Combining soil $\mathrm{C}$ and $\mathrm{N}$ spatial variability and modeling approaches for measuring and monitoring soil carbono sequestration. Environmental Management, v.33, p.274-288, 2004.
CFSMG - Comissão de Fertilidade do Solo do Estado de Minas Gerais. Recomendações para o uso de corretivos e fertilizantes em Minas Gerais - $5^{\mathrm{a}}$ aproximação. Viçosa, 1999. 359p.

Corá, J. E.; Beraldo, J. M. G. Variabilidade espacial de atributos do solo antes e após calagem e fosfatagem em doses variadas na cultura de cana-de-açúcar. Engenharia Agrícola, v.26, p.374-387, 2006.

Cunha, N. R. S.; Lima, J. E.; Gomes, M. F. M.; Braga, M. J. A intensidade da exploração agropecuária como indicador de degradação ambiental na região dos Cerrados, Brasil. Revista de Economia e Sociologia Rural, v.46, p.291-323, 2008.

Dias Filho, M. B. Sistemas silvipastoris na recuperação de pastagens degradadas. Belém: Embrapa Amazônia Oriental, 2006. 31p.

Dim, V. P.; Santos, A. C.; Neves Neto, D. N.; Silva, L. L.; Ramos, P. C.; Monteiro, F. P. R. Distribuição espacial de plantas daninhas e produção de forragem em áreas de pastejo contínuo. Revista Brasileira de Saúde e Produção Animal, v.12, p.296-305, 2011.

EMBRAPA - Empresa Brasileira de Pesquisa Agropecuária. Sistema brasileiro de classificação de solos. Brasília: Embrapa Produção de Informação, 2006. 306p.

EMBRAPA - Empresa Brasileira de Pesquisa Agropecuária. Manual de análises químicas de solos, plantas e fertilizantes. 2.ed. Brasília: Embrapa Comunicação para Transferência de Tecnologia, 2009. 627p.

Isaaks, E. H.; Srivastava, R. M. An introduction to applied geoestatistics. New York: Oxford University, 1989. 561p.

Islam, K. R.; Weil, R. R. Land use effects on soil quality ina tropical forest ecosystem of Bangladesh. Agriculture, Ecosystems \& Environment, v.79, p.9-16, 2000.

Kravchenko, A. N.; Robertson, G. P.; Snap, S. S.; Smucker. A. J. M. Using information about spatial variability to improve estimates of total soil carbon. Agronomy Journal, v.98, p.823-829, 2006.

Landim, P. M. B. Sobre geoestatística e mapas. Terra e Didática, v.2, p.19-33, 2006.

Lima, J. S. S.; Souza, G. S.; Silva, S. A. Amostragem e variabilidade espacial de atributos químicos do solo em área de vegetação natural em regeneração. Revista Árvore, v.34, p.127-136, 2010.

Machado, L. O.; Lana, A. M. Q.; Lana, R. M. Q.; Guimarães, E. C.; Ferreira, C. V. Variabilidade espacial de atributos químicos do solo em áreas sob sistema plantio convencional. Revista Brasileira de Ciência do Solo, v.31, p.591-599, 2007.

Matheron, G. Principles of geostatistics. Economic Geology, v.58, p.1246-1266, 1963.

Paz-Gonzalez, A.; Castro, M. T.; Vieira, S. R. Geostatistical analysis of heavy metals in a one-hectare plotunder natural vegetation in a serpentinearea. Canadian Journal of Soil Science, v.81, p.469-479, 2001.

Roque, C. G.; Centurion, J. F.; Alencar, G. V.; Beutler, A. N.; Pereira, G. T.; Andrioli, I. Comparação de dois penetrômetros na avaliação da resistência à penetração de um Latossolo Vermelho sob diferentes usos. Acta Scientiarum Agronomy, v.25, p.53-57, 2003. 
Santos, A. C.; Salcedo, I. H.; Candeias, A. L. B. Variabilidade espacial da fertilidade do solo sob vegetação nativa e uso agropecuário: Estudo de caso na microbacia Vaca Brava - PB. Revista Brasileira de Cartografia, v.62, p.119-124, 2010.

Sene, M.; Vepraskas, M. J.; Naderman, G. C.; Denton, H. P. Relation ships of soil texture and structure to corn yield response to sub soiling. Soil Science Society of America Journal, v.49, p.422-27, 1985.

Silva Neto, S. P.; Santos, A. C.; Leite, R. L. L.; Dim, V. P.; Cruz, R. S.; Pedrico, A.; Neves Neto, D. N. Análise espacial de parâmetros da fertilidade do solo em região de ecótonosob diferentes usos e manejos. Semina. Ciências Agrárias, v.32, p.541-552, 2011.

Souza, G. S.; Lima, J. S. S.; Silva, S. A.; Oliveira, R. B. Variabilidade espacial de atributos químicos em um Argissolosob pastagem. Acta Scientiarum Agronomy, v.30, p.589-596, 2008.
Souza, Z. M.; Campos, M. C. C.; Cavalcante, I. H. L.; Marques Júnior, J.; Cesarin, L. G.; Souza, S. R. Dependência espacial da resistência do solo à penetração e do teor de água do solo sob cultivo contínuo de cana-de-açúcar. Ciência Rural, v.36, p.128-134, 2006.

Vanni, S. M. Modelos de regressão: Estatística aplicada. São Paulo: Legmar Informática, 1998. 177p.

Vieira, S. R. Geoestatística em estudos de variabilidade espacial do solo. In: Novais, R. F.; Alvarez, V. H.; Schaefer, C. E. G. R. (ed.). Tópicos em ciência do solo. Viçosa: Sociedade Brasileira de Ciência do Solo, 2000. v1, p.1-53.

Virágh, K.; Tóth, T.; Somodi, I. Effect of slight vegetation degradation on soil properties in Brachy podium pinnatum grass lands. Plant Soil, v.345, p.303-313, 2011.

Warrick, A. W.; Nielsen, D. R. Sapatial variability of soil physical properties in the field. In: Hillel, D. (ed.). Application of soil physics. New York: Academic Press, 1980. p.319-344. 